Applied Remote Sensing

Latest decade's spatial-temporal properties of aerosols over China based on Multiangle Imaging SpectroRadiometer observations

Xingfa $\mathrm{Gu}$

Jing Guo

Tianhai Cheng

Tao $\mathrm{Yu}$

Hao Chen

Donghai Xie

$\mathrm{Yu} \mathrm{Wu}$ 


\title{
Latest decade's spatial-temporal properties of aerosols over China based on Multiangle Imaging SpectroRadiometer observations
}

\author{
Xingfa Gu, Jing Guo, Tianhai Cheng, Tao Yu, Hao Chen, \\ Donghai Xie, and Yu Wu \\ Chinese Academy of Sciences, Institute of Remote Sensing and Digital Earth, Beijing 100101, \\ China \\ cthy@irsa.ac.cn
}

\begin{abstract}
The analysis of the spatial-temporal variability and trends of aerosols over China based on $\sim 11$ years (February 2000 to December 2010) of Terra-Multiangle Imaging SpectroRadiometer (MISR) Level 3 aerosol products is the focus. The study shows that the MISR aerosol optical depth (AOD) is in good agreement with corresponding AOD from AERONET stations and suggests that MISR aerosol products have higher applicability compared with MODIS AOD products over China. The spatial-temporal distribution and trends for annual and seasonal AOD values over the middle and eastern regions of China are the main focus. The results of our analysis show the significant characteristics and seasonal variation of the aerosol distribution over the study areas. The seasonal distribution in AOD over the study areas is not consistent with the MODIS data. An insignificant trend (5.3\%) is observed over the whole study area during the study period. The larger positive tendencies are found in the Yangtze River Delta and the Pearl River Delta (PRD); the values increased by $24.4 \%$ and $18 \%$ and are considered to be significant with a confidence level of $>95 \%$. However, in contrast to the recently reported negligible AOD trends of 0.002 per decade using MODIS data over Sichuan, significant increasing trends of 0.046 per 11 years for MISR over the same areas have been measured. The analysis of seasonal variation revealed the seasonal trend in the AOD and the main types of aerosols. During spring, the largest increasing trend (30.2\%) is observed in the PRD with a stable composition of fine and coarse aerosols. A pronounced decreasing trend is found over Shanxi and decreased by $-18.7 \%$ in spring during the period, which has not been previously reported. MODIS-Terra currently shows artificial negative AOD trends over land. Therefore, trends derived from MODISTerra may not reflect the realistic decadal aerosol changes and variability. The study shows that seasonal distribution and trend analyses are inconsistent when using MISR AOD products and MODIS AOD products over study areas, which indicates that the analysis of aerosol variation using MISR sensors is necessary. (C) The Authors. Published by SPIE under a Creative Commons Attribution 3.0 Unported License. Distribution or reproduction of this work in whole or in part requires full attribution of the original publication, including its DOI. [DOI: 10.1117/1.JRS.7.073518]
\end{abstract}

Keywords: aerosol; Multiangle Imaging SpectroRadiometer; spatial-temporal properties; trend analysis; Fourier transform method; China.

Paper 12170 received Jun. 7, 2012; revised manuscript received Apr. 7, 2013; accepted for publication Jul. 9, 2013; published online Aug. 21, 2013.

\section{Introduction}

Atmospheric aerosols, which are ubiquitous particles suspended in the atmosphere, affect the global climatic system in many ways, including directly affecting the solar radiation reaching the ground and air quality and indirectly affecting the properties of clouds and cloud radiative forcing. ${ }^{1}$ The effects of aerosols may partially counterbalance global warming caused by greenhouse gases. ${ }^{1,2}$ However, the quantification of the effects is difficult because the physical, chemical, and optical properties of aerosols are highly variable in space and time due to their short atmospheric lifetime and inhomogeneous emission. ${ }^{3}$ The Intergovernmental Panel on Climate Change (IPCC) reported that the inadequate understanding of aerosols is a major contributor to uncertainty in the assessment of climate change. Therefore, the global aerosol distributions and annual and 
seasonal changes need to be evaluated to determine the changes in the patterns over time and the effect on the global climate. ${ }^{4}$ Therefore, continuous monitoring of aerosol properties is essential, especially for climatically sensitive regions such as China, which is considered to be a major worldwide source of both natural and anthropogenic aerosols. ${ }^{5,6}$

Satellite aerosol remote sensing is a rapidly developing technology that may provide good temporal sampling and superior spatial coverage relative to ground-based stations. Due to the sparse ground-based network, especially in China, increasing attention has been devoted to satellite-based aerosol observations. ${ }^{7}$ Complete spatial satellite-based data are essential to characterize the spatial variability of aerosol properties. ${ }^{5}$ However, the aerosol retrieved by satellites is not considered to be reliable over land surfaces where the main aerosol sources are located because of the difficulty in discriminating the aerosol contribution from the ground in top of atmosphere measurements. ${ }^{8-10}$

Over the last decade, many spatial-temporal aerosol studies have been performed to better understand the climate change in China. Xie reported statistically increasing aerosol optical depth (AOD) trends in spring and summer in north China annually during the period from 1982 to 2001 using the Total Ozone Mapping Spectrometer (TOMS). Su et al. ${ }^{6}$ analyzed the AOD distribution over 10 locations in East Asia using the yearly mean POLDER-AOD products during the period from 2005 to 2009 . Guo et al. ${ }^{7}$ analyzed the monthly AOD trends of TOMS and MODIS in China during the period from 1982 to 2006. However, existing satellite aerosol data, such as TOMS, are limited because it is recorded at the near-ultraviolet band to detect aerosols. ${ }^{5,11}$ Moreover, recent studies have suggested that larger uncertainties exist in the MODIS aerosol data, ${ }^{12,13}$ especially over cloudy regions. ${ }^{14}$ The MODIS Terra currently shows artificial negative AOD trends over land as reported by a number of MODIS team presentations. ${ }^{15}$

Compared with other satellites, the Multiangle Imaging SpectroRadiometer (MISR) is unique among the earth observing system (EOS)-era satellite instruments because it uses a combination of high spatial resolution, a wide range of along-track view angles, and high-accuracy radiometric calibration and stability ${ }_{1}^{16}$ which provides an alternative and robust approach for the study of aerosols over land surfaces. Prasad et al. ${ }^{17}$ found that MISR has been found to perform better than MODIS, which may attribute to its unique design (viewing and spectral capability) during the winter and summer seasons over the Indo-Gangetic basin. Liu et al. ${ }^{18}$ reported that MISR data are particularly suitable for determining the population exposure of dust storms in large urban centers in which the surface reflection is high and there is a lack of dense vegetation. Good agreement between the MISR and the Aerosol Robotic Network (AERONET) AOD is also obtained in the high surface reflectance regions over China, ${ }^{19}$ in contrast to the MODIS AOD. Validation studies on various terrain conditions against the ground data have illustrated that MISR is the most accurate satellite aerosol sensor. The global data sets produced by MISR instrument have contributed to the reduction in the uncertainties in aerosol transport and radiative impact modeling. ${ }^{20-24}$ However, most of the previously mentioned studies represent a lack of analysis concerning the distribution and the temporal variability of MISR AOD in China, especially in the analysis of seasonal variability and trends in AOD on a relatively long-term basis.

The objective of this study is to analyze the spatial and temporal variability of aerosols monthly, seasonally, and annually in central and eastern China based on more than 10-year period (February 2000 to December 2010) of MISR AOD products. The MISR AOD data and the assessment of its accuracy and the method used to estimate the AOD trend analysis are introduced in Sec. 2. The results of the analysis of the characteristics and seasonal variation of aerosol distribution and the long-term trends in the AOD data are shown in Sec. 3. Further discussions on the results are reported in Sec. 4.

\section{Data and Methodology}

\subsection{Data Set and Study Areas}

\subsubsection{MISR level 3 data collection and processing}

The MISR was launched aboard the NASA Earth Observing System's Terra spacecraft in December 1999 into a sun synchronous orbit that crosses the equator at about 10:30 AM 
local time and descends on the dayside of the planet. The MISR is unique among the EOS-era satellite instruments because it uses a combination of high spatial resolution, a wide range of along-track view angles, and high-accuracy radiometric calibration and stability. ${ }^{16}$ The subspace craft point, which reaches to \pm 82 deg latitude, is obtained about once per week. ${ }^{24}$ The orbit number is a sequential counter related to the time of data acquisition; $\sim 14.56$ orbits are completed each day, which equals $\sim 5315$ orbits per year. The MISR observes the Earth and atmosphere with nine different viewing angles pointed toward the Earth at $\pm 70.5, \pm 60.0, \pm 45.6$, and $\pm 26.1 \mathrm{deg}$ and nadir along the spacecraft ground track. The MISR measures upwelling short wave radiance from Earth in four spectral bands, centered at 446, 558, 672, and $866 \mathrm{~nm}$. Over a period of $7 \mathrm{~min}$, as the spacecraft travels above the surface, a $380-\mathrm{km}$ wide swath of Earth is successively viewed by each of the MISR's nine cameras. As a result, the instrument samples a large range of scattering angles between $\sim 60$ and 160 deg at midlatitudes that provide information on the aerosol microphysical properties. ${ }^{24}$

The AOD retrievals from the 558-nm channel were used in the study for the period ranging from February 2000 to December 2010. The aerosol data used are a part of the MISR level 3 daily gridded atmospheric data product with horizontal resolution $0.5 \times 0.5$ deg and are produced from higher order level 2 data (17.6 km for MISR). The MISR standard aerosol retrieval algorithm searches a database of TOA radiances simulated for the MISR channels, solar position, and viewing geometries assuming a range of candidate aerosol mixtures and optical depths and compares the database with the observed radiances. ${ }^{24-26}$ The MISR 558-nm (green band) regional AOD has been extensively validated and is generally consistent with AEROENT. The global comparisons between the MISR and AERONET data show that the MISR green band AOD values fall within 0.05 or $20 \% \times$ AOD of AERONET and $~ 40 \%$ are within 0.03 or $10 \% \times$ AOD ${ }^{27,28}$ However, studies evaluating the MISR quality are limited over China, especially when comparing the MISR and MODIS aerosol products to assess the applicability of both sensors. Many studies focus on the validation and spatial-temporal properties of MODIS aerosol products. In this study, we analyze the differences between the MISR and MODIS AOD data using AERONET data sets to determine which sensor is more accurate over China. Figure 1 presents the areas of the study and five available AERONET sites in China, including Beijing, Xianghe, Xinglong, Thaihu, SACOL, and Hong Kong. Combining these sites enhances the reliability of our comparison. ${ }^{6}$ First, 9 years (2002 to 2010) of MODIS and MISR aerosol retrieval data over land were collocated with all the available level 2 AERONET data. We selected AERONET AOD data matching roughly within $30 \mathrm{~min}$ of the local satellite overpass time. This paper adopts a reasonable method that searches the satellite aerosol pixel closest to an AERONET location and pairs the corresponding "closest" satellite AOD. The correlation coefficient, and slope of the satellite-derived AOD and AERONET measurements in five stations are shown in Fig. 1. The scatter plots reveal that the MISR and MODIS data over land demonstrate a high correlation coefficient of $>0.9$ and are consistent with AERONET. The MISR AOD data also exhibit higher correlation coefficients (0.94) and lower root mean square error (RMSE) than the MODIS AOD data. Table 1 gives detailed information on the validation results of both the MISR and MODIS data compared with the AERONET data based on six sites. The results show
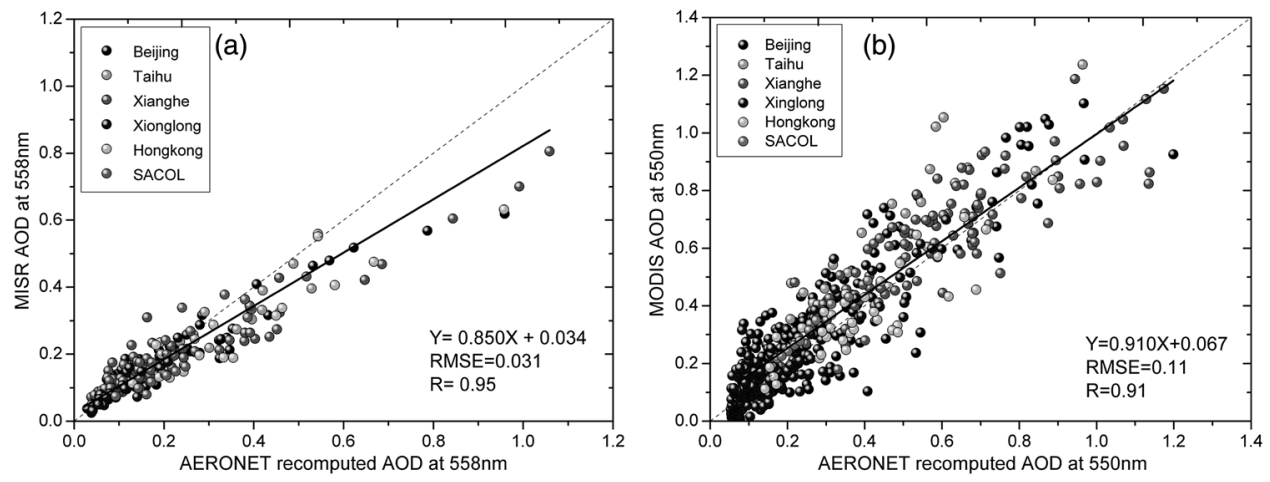

Fig. 1 Comparisons between MISR, MODIS, and AERONET AOD at $550 \mathrm{~nm}$ over China, from July 2000 to December 2010. 
Table 1 Statistics of the MISR and MODIS AOD data from the AERONET measurements (March 2002 to December 2010).

\begin{tabular}{|c|c|c|c|c|c|}
\hline & Mean & Value & & & \\
\hline Site & AERONET & MISR & $R$ & RMSE & Slope \\
\hline Beijing & $0.21 \pm 0.16$ & $0.19 \pm 0.12$ & 0.95 & 0.03 & 0.86 \\
\hline Xianghe & $0.21 \pm 0.21$ & $0.19 \pm 0.14$ & 0.96 & 0.04 & 0.82 \\
\hline Xinglong & $0.09 \pm 0.05$ & $0.08 \pm 0.05$ & 0.92 & 0.02 & 0.91 \\
\hline Taihu & $0.34 \pm 0.12$ & $0.30 \pm 0.10$ & 0.91 & 0.04 & 0.81 \\
\hline SACOL & $0.27 \pm 0.12$ & $0.23 \pm 0.12$ & 0.91 & 0.04 & 0.95 \\
\hline \multirow[t]{2}{*}{ Hongkong } & $0.38 \pm 0.22$ & $0.28 \pm 0.16$ & 0.93 & 0.05 & 0.88 \\
\hline & Mean & Value & & & \\
\hline Site & AERONET & MODIS & $R$ & RMSE & Slope \\
\hline Beijing & $0.28 \pm 0.23$ & $0.3 \pm 0.21$ & 0.88 & 0.10 & 0.89 \\
\hline Xianghe & $0.17 \pm 0.13$ & $0.33 \pm 0.24$ & 0.94 & 0.08 & 1.02 \\
\hline Xinglong & $0.25 \pm 0.21$ & $0.18 \pm 0.16$ & 0.89 & 0.07 & 1.10 \\
\hline Taihu & $0.47 \pm 0.20$ & $0.67 \pm 0.24$ & 0.88 & 0.12 & 1.07 \\
\hline SACOL & $0.37 \pm 0.18$ & $0.52 \pm 0.20$ & 0.93 & 0.13 & 0.80 \\
\hline Hongkong & $0.39 \pm 0.17$ & $0.37 \pm 0.16$ & 0.86 & 0.08 & 0.81 \\
\hline
\end{tabular}

that the MISR data are more consistent with the AERONET data for most of the stations compared with the MODIS data, except for the SACOL station in which the MODIS retrieval over the land was biased high.

There are several observed differences between the different aerosol estimates in comparing the MISR and MODIS AOD data with the AERONET data. The sensor characteristics, the complex surface, and aerosol models that are used in the retrieving process would contribute to the differences. According to some studies, the instrument issue should be considered in the different algorithms in both the MISR and MODIS data because the instruments collect unique information content (e.g., spatial resolutions and polarization). The MISR observes the same point on the Earth at nine different angles and four spectral bands. The MODIS observes the same point in a single direction but in 36 channels covering a wide spectral range.

The MISR algorithm uses a prescribed set of aerosol models considered to be representative of the types found across the globe and determines the models and optical depths to use for each model. ${ }^{29}$ The MISR uses an empirical orthogonal function representation of the region-averaged surface-leaving light reflection to separate the surface-leaving light reflection from the atmosphere-leaving light reflection over land.

The MODIS retrievals over land are based on the correlation of reflectances in the visible and midinfrared range. ${ }^{30}$ The empirical relationship between the surface reflectance for both bands is consistent for most of the dark surfaces. However, the current operational MODIS retrieval tends to be limited by the lack of dense vegetation on the ground. In conclusion, the MISR provides a better tool to study the aerosol abundance in deserts or densely populated urban centers where high surface reflection is common.

Overall, these results show that the MISR aerosol data are consistent with the ground-based AOD data and are more applicable than the MODIS aerosol retrievals over China, which indicate that the MISR aerosol products are reliable for studying the spatial-temporal distributions over China.

In this work, which ranges from $\left(19\right.$ to $45^{\circ} \mathrm{N}, 100$ to $\left.136^{\circ} \mathrm{E}\right)$, the study areas cover almost all of eastern China. The spatial distribution, seasonal variation, and trends of aerosols in the AOD 
data over middle and eastern China are studied using MISR aerosol products from 2000 to 2010 .

\subsubsection{Study areas}

Central and eastern China is an important study region for aerosols, which exerts a strong anthropogenic effect. Moreover, the region mixes different types of aerosol particles, such as anthropogenic aerosols from developed areas, desert dust from the north, and maritime aerosols. In this paper, typical regions rather than the whole country are selected for long-term trend analysis to more precisely analyze aerosol patterns in regions including Jingjintang (1:JJT), Yangtze River Delta (2:YRD), Pearl River Delta (3:PRD), Sichuan Basin (4:SC), Guangxi (5:GX) and Shanxi (6:SX), as shown in Fig. 2. Jingjintang has commonly experienced dust events in recent years. The Sichuan Basin is surrounded by mountains, and the anthropogenic emission contributes to most of the atmospheric pollution. Shanxi is a coal-producing province located west of Beijing. The six regions were selected to analyze the long-term trends to understand the cause of variation in the AOD data.

\subsection{Method of Trend Analysis}

In this paper, we will study the statistical linear tendency of the AOD. The actual tendencies of the AOD data may be much more complex than the statistical linear model. ${ }^{4}$ However, the linear trend allows a simple approximation of the direction and magnitude of the changes in the data. It is important to examine the significance of the trend analysis. We estimate the confidence of the trend analysis using the method by Weatherhead et al. ${ }^{31}$ and will focus on its application in analyzing the long-term MISR aerosol observations. The aerosol trend for the study period is represented using the following equations:

$$
Y_{t}=Y_{0}+\omega X_{t}+N_{t} \quad t=1, \ldots T
$$
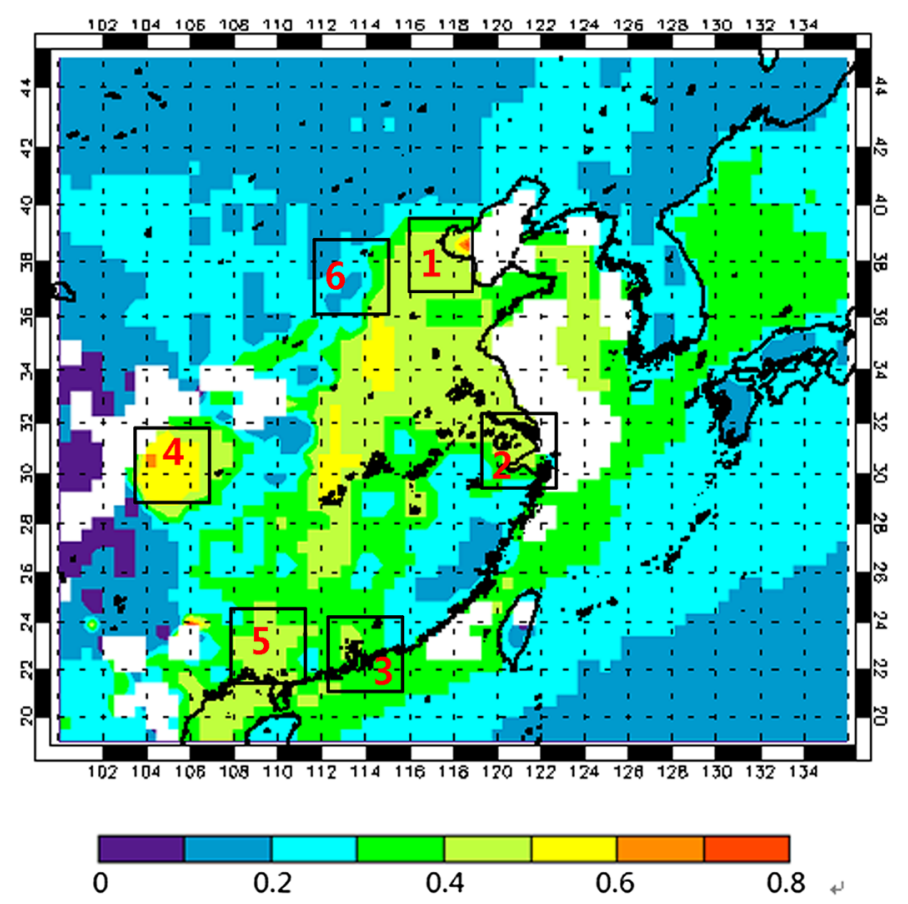

Fig. 2 Spatial distribution of AOD at green band based on MISR products over a 10-year period (July 2000 to December 2010). Map of the study areas, (1) Jingjintang, (2) Yangtze River Delta, (3) Pearl River Delta, (4) Sichuan basin, (5) Guangxi, and (6) Shanxi. The white areas correspond to $0.5 \times 0.5 \mathrm{deg}$ longitude-latitude geographical cells with $<50 \%$ of total number of data. 
and

$$
N_{t}=\varphi N_{t-1}+\epsilon_{t}
$$

In the method, $Y_{t}$ is the monthly mean global averaged over-land MISR AOD data in each area of examination, $\omega$ is the linear AOD trend, and $Y_{0}$ is the offset at the start of the time series. $T$ is the total number of months, $X_{t}$ equals the number of years since February 2000 and $t$ is the monthly index. $N_{t}$ is the monthly mean noise, and Eq. (2) is assumed to be autoregressive of the order of the model. The noise is autocorrelated among successive measurements, where $\varphi$ is the autocorrelation between $N_{t}$ and $N_{t-1}, \varepsilon_{t}$ represents independent random variables. Based on Eqs. (1) and (2), Weatherhead et al. ${ }^{31}$ suggested that the standard deviation of the yearly trend $\left(\sigma_{\omega}\right)$ can be estimated as

$$
\sigma_{\omega} \approx \frac{\sigma_{N}}{n^{3 / 2}} \sqrt{\frac{1+\phi}{1-\phi}} .
$$

In Eq. (3), $\omega$ is the slope of the linear regression line for the time series of monthly or annually averaged AOD, ${ }^{32}$ and $n$ denotes the number of years of data. This paper shall adopt the commonly used decision rule that a real trend is indicated at the 5\% significance level or $95 \%$ confidence level when $|\omega / \sigma|>2$ (see Ref. 31) in which $\sigma$ is the standard deviation of $\omega$. It is difficult to determine $\sigma$ from the observational data directly; therefore, as a first-order approximation, we use the standard deviation of the monthly (or annually) averaged AOD data as $\sigma$ to match the unit of $\omega$. We define $|\omega / \sigma|$ as the significance of $\omega$. A significance greater than +2 (or less than -2) indicates an increasing (or decreasing) tendency detected above the $95 \%$ confidence level.

The $\triangle \mathrm{AOD}$ variable can be used to quantitatively describe the change (in relative percentage) of the AOD. It compares the current AOD values with the initial AOD, which are calculated by applied linear regression based on the time series of the annual mean AOD. It can be expressed as follows:

$$
\Delta \mathrm{AOD}=\frac{\operatorname{AOD}\left(x_{2}\right)-\operatorname{AOD}\left(x_{1}\right)}{\operatorname{AOD}\left(x_{1}\right)}(100)
$$

where $x_{1}$ and $x_{2}$ represent the beginning and ending times, respectively.

\section{Results and Discussion}

\subsection{Characteristics of the MISR AOD Distribution over China}

With rapid economical development and dense human activities, anthropogenic and natural aerosols accumulate in China. In this paper, 11 years (February 2000 to December 2010) of MISR aerosol data are applied to analyze the characteristics of the spatial-temporal distribution of aerosols and the seasonal variability over China.

Figure 2 shows the spatial distribution of the averaged AOD data over central and eastern China using the MISR aerosol data. Note that the information given in this figure is of climatological importance because it is the first study to analyze MISR AOD data over a relatively long period over China. The AOD data are not available during $\sim 11$ years in the grids colored white.

As shown in Fig. 2, the high averaged AOD values (0.5 to 0.8 ) mainly appear in the middle of China, the Sichuan basin, and southern China, which experience intense anthropogenic activity and are economically developed. The computed mean regional annual value of AOD for middle and eastern China is $0.28 \pm 0.06$ in which the standard deviation indicates the significant temporal variability. This value is larger than the global mean AOD value of $0.12 \pm 0.04$ as observed by satellite, ${ }^{33}$ which indicates that China has become one of the largest aerosol loads in the world. ${ }^{34}$ The lower AOD values primarily appear over northeast China. In general, larger AOD values occur over continental rather than maritime regions. Similar patterns of spatial 
distribution of the AOD data have been demonstrated by studies of other researchers using different satellite data (e.g., Refs. 6, 7, 35). The analysis of interannual variation is presented more precisely from the aspect of seasons (Fig. 3) in which spring (MAM), summer (JJA), autumn $(\mathrm{SON})$, and winter (DJF) are separated.

Figure 3(a) shows the spatial-temporal distribution of aerosols in spring. The maximum AOD values (0.6 to 0.7 ) occur over Sichuan and Guangxi, and higher AODs ranging from 0.5 to 0.6 mostly appear in Jingjintang, the YRD, and central China. The mean regional AOD value in spring is $0.37 \pm 0.12$ and covers the entire study areas. Large AOD values in the Sichuan basin are related to the dense population and unique topography, which contributes to the accumulation of aerosol pollutants. In Guangxi and PRD, the large AODs are consequences of the burning of biomass in Southeast Asia. ${ }^{22,20}$ Because of industrialization, urbanization, and dust emissions, the aerosol loading in regions with higher AOD values increased rapidly. Along with local aerosol emissions, dust particles may be transported to eastern China following the dominant westerly wind during spring. ${ }^{22,35}$ This may contribute to the high AOD in the YRD.

Figure 3(b) shows the spatial distribution of AOD in summer. The AOD values increase significantly in middle and eastern China, especially around the border of the Hunan and Hubei provinces in which the AOD values are larger in summer than in spring. The mean regional AOD in summer is $0.41 \pm 0.14$. The maximum AOD values occur in summer due to two factors: aerosol emission is dominated by mixtures of anthropogenic and dust aerosol, and the low influx of air cannot remove aerosol pollutions. ${ }^{7}$ In contrast, the AOD values decreased significantly in summer around the Sichuan Basin, the PRD and the Guangxi

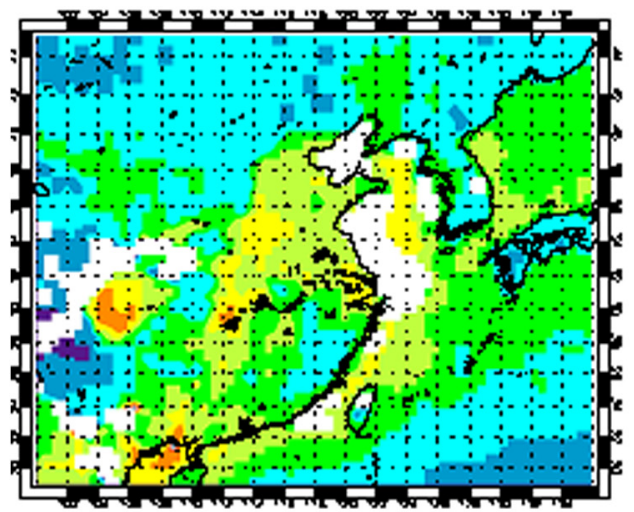

(a) Spring

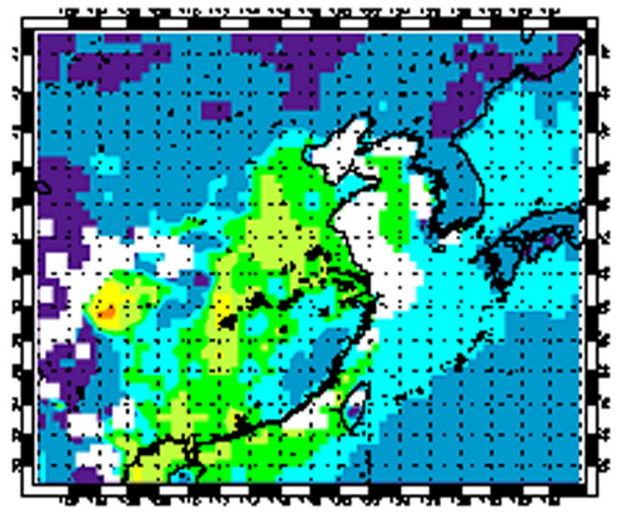

(c) Autumn

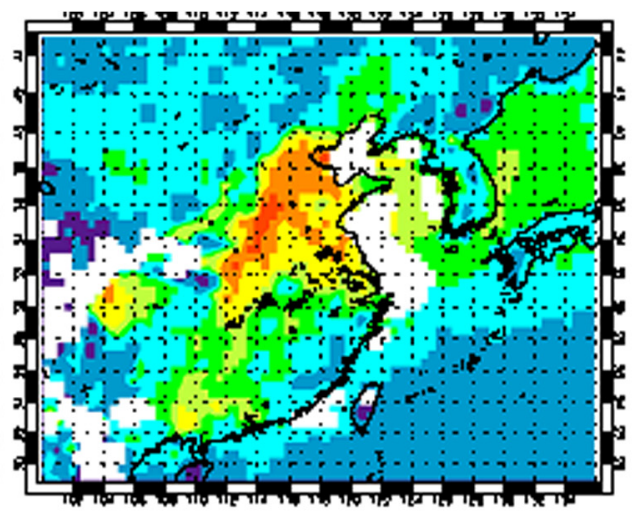

(b) Summer

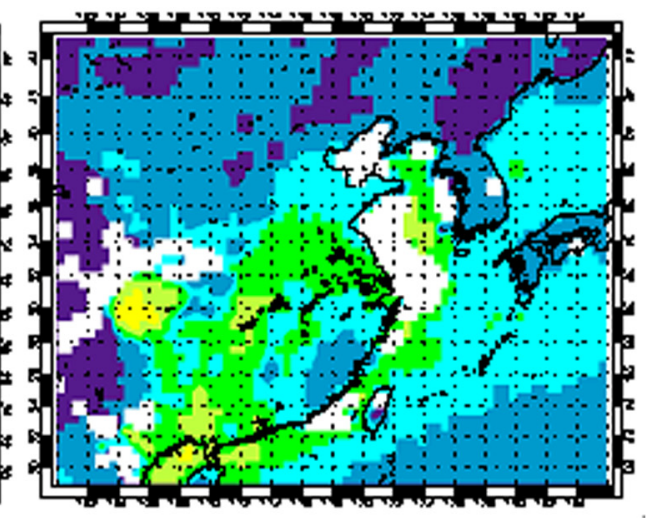

(d) Winter

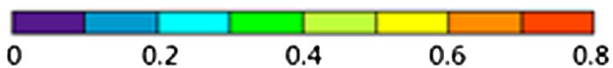

Fig. 3 Spatial distribution characteristics of MISR AOD at $550 \mathrm{~nm}$ over China for (a) spring (March to May), (b) summer (June to August), (c) autumn (September to November), and (d) winter (December to February). 
compared to the spring season. The AOD values decreased in summer because a large amount of aerosol is removed from the atmosphere due to frequent rainfall and atmospheric circulation. ${ }^{35}$

In autumn, the AOD decreases dramatically in middle and eastern China. The regional AOD value decreases from 0.8 to 0.4 in autumn. The average regional AOD is $0.33 \pm 0.13$ for the entire study area. The high AOD values detected in summer are barely visible in autumn. The photochemical interactions are less active because of lower air temperatures which decrease the aerosol concentrations in the atmosphere in autumn. ${ }^{7,34}$

In winter [Fig. 3(d)], the averaged AOD values decreased and reached a minimum in most parts of China. The mean seasonal regional AOD in winter is $0.29 \pm 0.10$. The AOD values decrease from autumn to winter because the ice-snow cover on the ground prevents the emission of soil dust. ${ }^{35}$ In addition, frequent cold air from the north often brings clean air into middle and eastern China, which removes pollutants. ${ }^{35}$

Based on the previously mentioned research, it is clear that the aerosol patterns detected by MISR over China are linked with human activities and the seasonal change of natural sources. The same characteristics and seasonal variations also occur in AOD data with different wavelength bands.

\subsection{Analysis and Changes for the Entire Study Area from MISR Products}

The time series of the daily regional values of MISR AOD over the entire study area from 2000 to 2010 is shown in Fig. 4. The AOD trend obtained from linear regression of the AOD values reveals a small increasing trend of 5.3\%, which indicates a slight increase in the aerosol loads over central and eastern China during the period. A significant seasonal cycle was observed, which increases from spring to summer and decreases from autumn to winter. The high aerosol loads in spring and summer are mainly associated with dust aerosol and increasing aerosol concentrations as a result of higher air temperatures. The study shows that an abnormal value ( 0.58) in spring of 2003 is associated with significant dust activity in Asia. ${ }^{32}$

The spatial distribution of the trends and changes of AOD over central and east China is shown in Fig. 5. The trends and changes were calculated from the linear regressions of the time series of AOD for each of the over 4000 grid points. The significant increasing trends mainly occur over land, whereas the slightly decreasing trends appear over the ocean. Over the studied areas, there is no remarkable correlation between the increasing trend and the distribution of the AOD; however, the significant increase in the trends and variation of the AOD $(\triangle \mathrm{AOD})$ occurs in the areas with dense population and rapid development. The increasing trends appear more rapidly in the Sichuan, Guangxi, Hunan and eastern Guizhou provinces, while the regions with low AOD values often present decreasing trends.

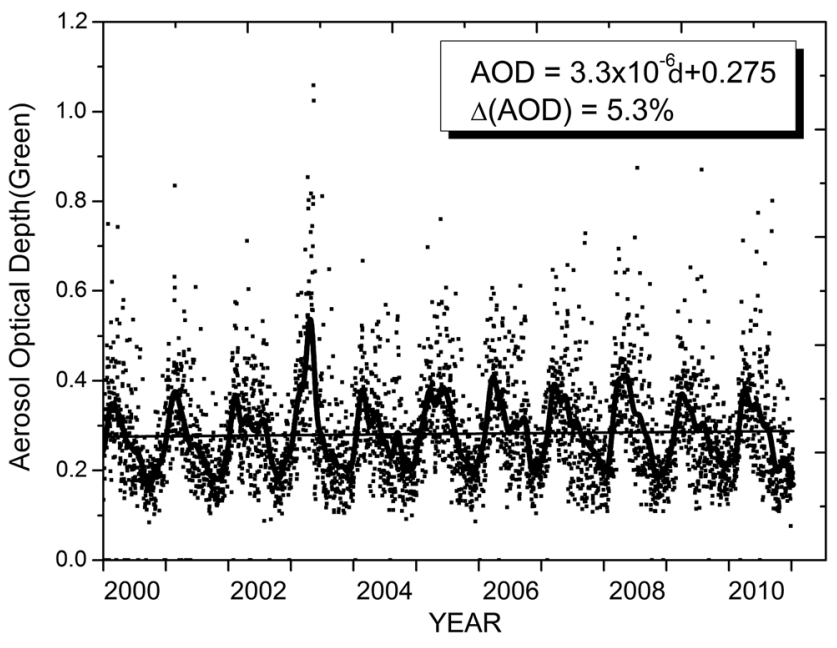

Fig. 4 The dots represent study period of computed daily regional mean values in AOD over China using MISR data. The blue line based on 30-day moving averages, and the linear regression (red line) to the time series of $A O D$ is shown. 

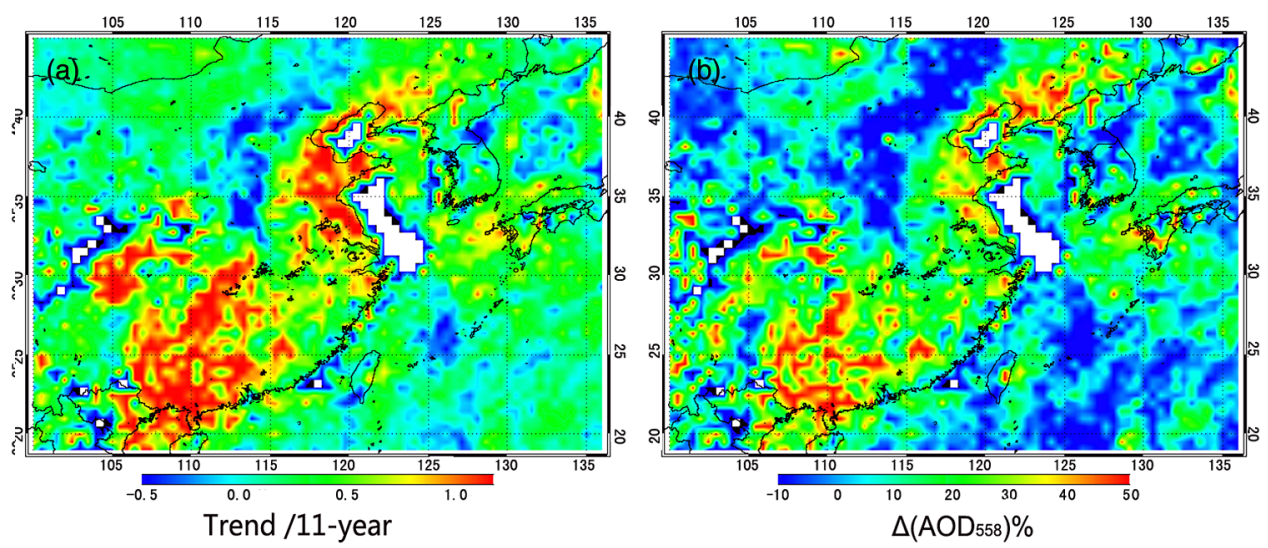

Fig. 5 Spatial distribution of $A O D$ trends during study period. (a) The trends of $A O D \times 100$ are plotted with the use of MISR AOD data and (b) change of AOD (in relative percentage term) over middle and east of China.

The change in the AOD is more visible in Sichuan, Shandong, Jingjintang and eastern China and areas surrounding Shanghai with increases of more than $25 \%$.

\subsection{Seasonal Distribution and Variations of the AOD over Central and Eastern China}

Given the influence of season, we analyze the seasonal distribution of the AOD in six regions of China. Six regions with typical characteristics are Jingjintang (JJT), Yangtze River Delta (YRD), Pearl River Delta (PRD), Sichuan (SC), Guangxi (GX), and Shanxi (SX).

In Fig. 6, the seasonal characteristics are represented by the AOD in six regions. The spring and summer exhibit higher AOD compared with the other seasons. The minimum AOD occurs in winter for most of the six regions except for PRD. In the JJT, YRD, and SX regions, the AOD values vary dramatically for seasons and exhibit generally similar seasonality. Therefore, the AOD values in the three regions are influenced by similar aerosol sources. Our results also verify that the AOD values for the typical regions decrease in autumn and winter compared with spring and summer.

The finding of this analysis indicates that the seasonal patterns over YRD, PRD, and SC are inconsistent with the results reported by Guo et al. using MODIS data from 2000 to 2008.

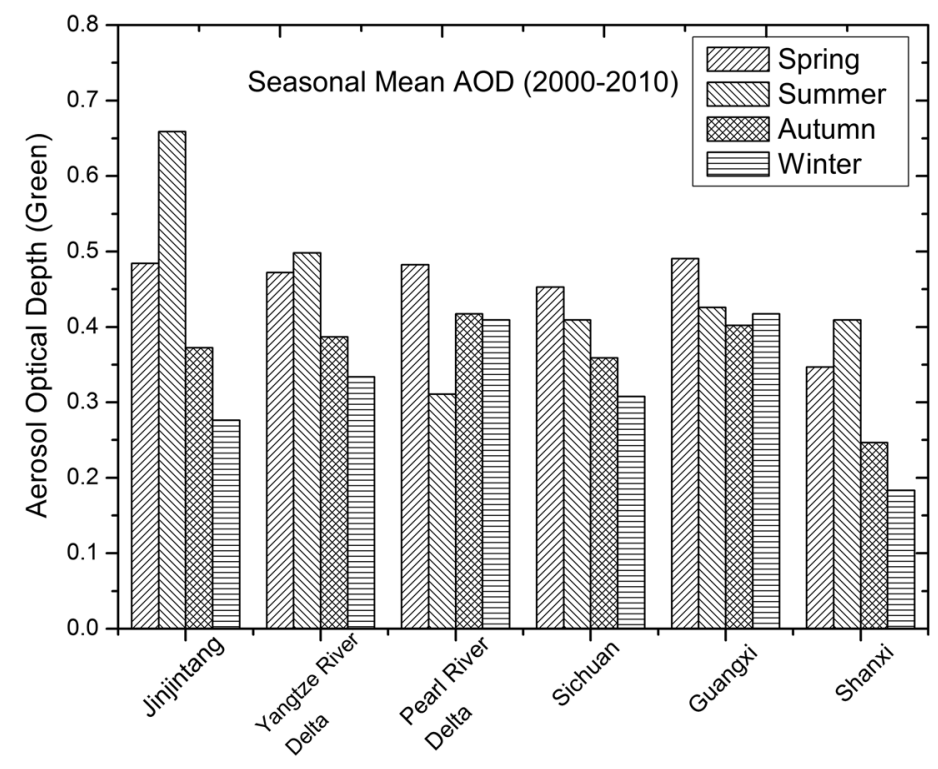

Fig. 6 Seasonal means distribution of MISR AOD during July 2000 to December 2010. 


\subsection{Regional Analysis from MISR Products}

To further investigate the AOD changes, six regions with typical characteristics are analyzed to discuss the trends of the AOD (558 nm) and $\AA \mathrm{E}$ (558 to $875 \mathrm{~nm})$ data.

Figure 7 represents the monthly averaged Terra MISR trends of the AOD and ÅE over JJT, YRD, PRD, SC, GX, and SX during the study period. The thin lines represent the monthly averaged AOD values from the aerosol products, and the thick solid lines show the fast Fourier transform (FFT) analysis for the monthly averaged AOD values over the study regions. A linear regression analysis was applied to the FFT method to reveal the AOD trend.

The increasing trends in the AOD data are detected for most of the regions except for SX. The largest positive tendencies are found for JJT and YRD. The AOD and ÅE values over the six typical areas exhibited the strongest seasonality. The decreasing trends of the ÅE data are observed for PRD and GX, which indicate that the proportion of fine particles decreased. We also found that the compositions of aerosols are relatively stable for the other regions due to no significant trends in the ÅE values.

Over JJT, the regular changes could be easily distinguished using FFT analysis. With its relatively clean air, the YRD decreases and exhibits more stable annual variation in the AOD data compared with JJT during the study period. The AOD increased by $0.00072 /$ month over this region with a $|\omega / \sigma|$ value of much $>2$. Because of the rapid development of regional industrialization, ${ }^{36}$ the aerosol loading over GX and the PRD increased rapidly, and the magnitude of the trend is higher than 0.00048 /month. As shown by FFT analysis, both regions exhibit similar annual cycles and AOD trends. The AOD values over SC exhibit a significant increasing trend of $0.00046 /$ month as shown in Fig. 7(d). However, the positive
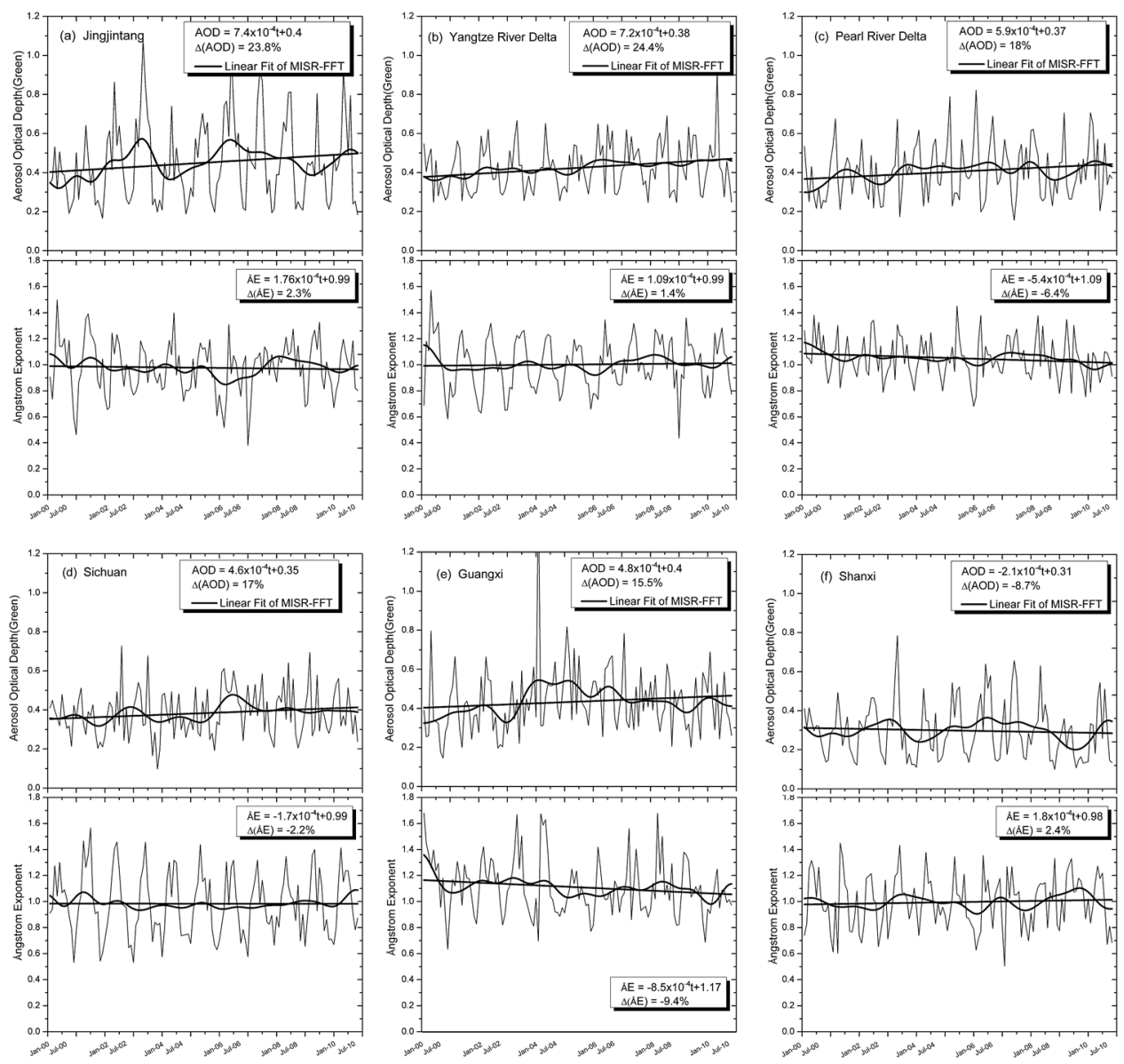

Fig. 7 Trend analysis of AOD and ÅE using Terra MISR aerosol product (blue line) over study period. The thin line shows monthly mean AOD and ÅE using MISR aerosol product, and the thick solid line shows FFT analysis. 
Gu et al.: Latest decade's spatial-temporal properties of aerosols over China...

tendency in the AOD is inconsistent with the negligible trend reported by Guo et al. using the MODIS data from 2000 to 2008 over SC.

In SX, the Olympic Games (2007 to 2009) contributed to a decreasing trend of the AOD values during the study period, which is likely related to the policy of emission reduction enforced by the government of the provinces and cities surrounding Beijing.

The results of the trends and variations with other wavelength bands are consistent with the results at $558 \mathrm{~nm}$ over the study areas. The MISR AOD values decreased, and the rate of the changing trend decreased with increasing wavelengths. The trends of the MISR AOD data with different wavelengths for the study regions are shown in Table 2.

\subsection{Seasonal Variations and Trends}

To better understand the factors leading to the AOD change, an analysis of the interannual variation of the AOD values on a seasonal basis were repeated. ${ }^{5}$ We separate the AOD data into two groups: the spring dataset (March to May) and the winter dataset (December to February). The seasonal trends in AOD for the study areas are presented in Fig. 8. Corresponding values of the seasonal trends in $\AA \mathrm{E}$ are presented in Table 3 .

Figure 8(a) shows more detailed information for the study areas during spring.

Table 2 Trend analysis for the selected target regions with different wavelengths.

\begin{tabular}{|c|c|c|c|c|c|c|}
\hline & \multicolumn{3}{|c|}{ Jinjintang } & \multicolumn{3}{|c|}{ Yangtze River Delta } \\
\hline & $\begin{array}{l}\text { Mean } \\
\text { value }\end{array}$ & $\begin{array}{l}\text { Trend } \\
\text { (/month) }\end{array}$ & $\begin{array}{c}\text { Change } \\
(\%)\end{array}$ & $\begin{array}{l}\text { Mean } \\
\text { value }\end{array}$ & $\begin{array}{l}\text { Trend } \\
\text { (/month) }\end{array}$ & $\begin{array}{c}\text { Change } \\
(\%)\end{array}$ \\
\hline AOD440 & $0.57 \pm 0.25$ & 0.00087 & 22.6 & $0.54 \pm 0.15$ & 0.0009 & 22.5 \\
\hline AOD558 & $0.48 \pm 0.13$ & 0.00074 & 23.8 & $0.48 \pm 0.16$ & 0.00072 & 24.4 \\
\hline AOD675 & $0.37 \pm 0.17$ & 0.00063 & 23.2 & $0.35 \pm 0.10$ & 0.00059 & 19.7 \\
\hline AOD865 & $0.29 \pm 0.13$ & 0.00048 & 22.1 & $0.27 \pm 0.08$ & 0.00045 & 24.6 \\
\hline \multirow[t]{3}{*}{ ÅE } & $0.98 \pm 0.20$ & 0.00018 & 2.3 & $1.00 \pm 0.20$ & 0.00011 & 1.4 \\
\hline & \multicolumn{3}{|c|}{ Pearl River Delta } & \multicolumn{3}{|c|}{ Sichuan } \\
\hline & $\begin{array}{l}\text { Mean } \\
\text { value }\end{array}$ & $\begin{array}{l}\text { Trend } \\
\text { (/month) }\end{array}$ & $\begin{array}{c}\text { Change } \\
(\%)\end{array}$ & $\begin{array}{l}\text { Mean } \\
\text { value }\end{array}$ & $\begin{array}{l}\text { Trend } \\
\text { (/month) }\end{array}$ & $\begin{array}{c}\text { Change } \\
(\%)\end{array}$ \\
\hline AOD440 & $0.51 \pm 0.17$ & 0.00068 & 19.0 & $0.48 \pm 0.15$ & 0.00055 & 19.2 \\
\hline AOD558 & $0.47 \pm 0.08$ & 0.00059 & 18.0 & $0.42 \pm 0.10$ & 0.00046 & 17.0 \\
\hline AOD675 & $0.33 \pm 0.12$ & 0.00052 & 21.9 & $0.32 \pm 0.10$ & 0.00039 & 21.7 \\
\hline AOD865 & $0.26 \pm 0.09$ & 0.00044 & 24.1 & $0.25 \pm 0.08$ & 0.00031 & 18.3 \\
\hline \multirow[t]{3}{*}{ ÅE } & $1.10 \pm 0.15$ & -0.00054 & -6.4 & $0.98 \pm 0.24$ & -0.00017 & -2.2 \\
\hline & \multicolumn{3}{|c|}{ Guangxi } & \multicolumn{3}{|c|}{ Shanxi } \\
\hline & $\begin{array}{l}\text { Mean } \\
\text { value }\end{array}$ & $\begin{array}{l}\text { Trend } \\
\text { (/month) }\end{array}$ & $\begin{array}{c}\text { Change } \\
(\%)\end{array}$ & $\begin{array}{l}\text { Mean } \\
\text { value }\end{array}$ & $\begin{array}{l}\text { Trend } \\
\text { (/month) }\end{array}$ & $\begin{array}{c}\text { Change } \\
(\%)\end{array}$ \\
\hline AOD440 & $0.56 \pm 0.21$ & 0.00051 & 13.1 & $0.38 \pm 0.18$ & -0.0025 & -7.2 \\
\hline AOD558 & $0.43 \pm 0.06$ & 0.00048 & 15.5 & $0.30 \pm 0.14$ & -0.00021 & -8.7 \\
\hline AOD675 & $0.35 \pm 0.15$ & 0.00046 & 20.4 & $0.25 \pm 0.12$ & -0.0002 & -6.8 \\
\hline AOD865 & $0.27 \pm 0.12$ & 0.00042 & 22.7 & $0.19 \pm 0.09$ & -0.000019 & -5.7 \\
\hline ÅE & $1.11 \pm 0.22$ & -0.00085 & -9.4 & $1.00 \pm 0.20$ & 0.00018 & 2.4 \\
\hline
\end{tabular}


The aerosol load tends to increase over JJT, PRD, and SC, whereas it is decreasing over YRD, GX and SX. The largest increasing trend of 30.2\% every 11 years is observed over PRD. The increasing trends of the ÅE are observed for most of the study areas except for PRD and GX where relatively higher ÅE values were observed.

The AOD variation in YRD exhibited a decrease of $-9.1 \%$, which corresponded with a significant increase of the $\AA \mathrm{E}$. The decreasing trend in the AOD values may be partially the result of decreasing coarse aerosol, such as dust aerosol. The ÅE trend for JJT is similar to YRD but with small aerosol loading, which may demonstrate that the effect of dust aerosols is waning for the above described stations. Over PRD and GX, small particles are the dominant aerosol. The AOD values over GX tend to decrease (-16.7\%/11-year) due to a decrease in small particles, which is probably related to decreases in fine aerosol loads, such as biomass burning. The AOD over SX, where the proportion of coarse particles descends, tends to be significantly decreasing.

Figure 8(b) shows patterns similar to Fig. 8(a) but for winter. The AOD variations show increasing trends over the study areas except for SX. The largest trend of $0.00059 /$ month is found for GX, and the $|\omega / \sigma|$ value is $>2$ with a $95 \%$ confidence level. Weather patterns instigating serious pollution events usually occur in SC Basin, ${ }^{20}$ which causes larger increases in the AOD. The ÅEs for JJT, YRD, and SC show positive tendencies with low values, and the AOD growth trends are correlated with decreasing coarse-mode particles. Additionally, the aerosol components are relatively stable with negligible trends in the $\AA \mathrm{E}$ for the other regions. The ÅEs in winter are lower than in spring, which indicates that coarse particles are dominant during winter.
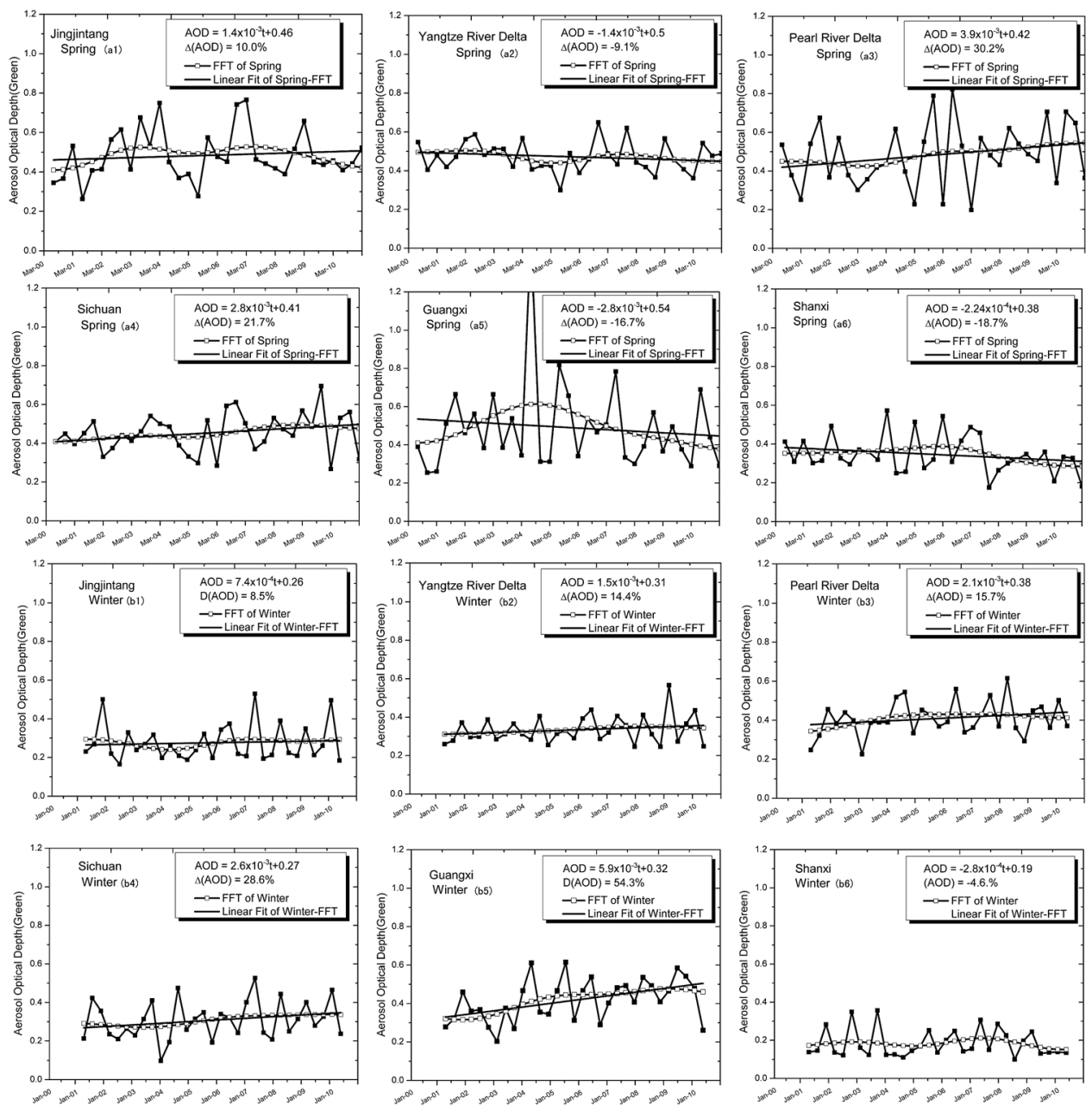

Fig. 8 Time series (2000 to 2010) of monthly MISR AOD during spring (March to May) and winter (November to March). The linear regressions to the time series of AOD are also shown. 
Gu et al.: Latest decade's spatial-temporal properties of aerosols over China...

Table 3 Eleven-year ÅE trend analysis for the six typical regions. All changes are given for the spring (March to May) and winter (December to February) seasons.

\begin{tabular}{|c|c|c|c|c|}
\hline & $\begin{array}{l}\text { Slope spring } \\
\AA \mathrm{E} / \text { month }\end{array}$ & $\begin{array}{c}\text { Slope winter } \\
\AA \mathrm{E} / \text { month }\end{array}$ & $\begin{array}{c}\text { Spring change } \\
\text { of } \AA \mathrm{E}(\%)\end{array}$ & $\begin{array}{l}\text { Winter change } \\
\text { of } \AA E(\%)\end{array}$ \\
\hline Jingjintang & 0.0017 & 0.0025 & 6.1 & 9.5 \\
\hline Yangtze River Delta & 0.0056 & 0.003 & 20.2 & 12.1 \\
\hline Pearl River Delta & -0.00028 & -0.00038 & -0.8 & -1.3 \\
\hline Sichuan & 0.0025 & 0.0039 & 7.9 & 17.9 \\
\hline Guangxi & -0.0058 & 0.000176 & -13.8 & 0.6 \\
\hline Shanxi & 0.0049 & -0.000287 & 18.8 & -0.93 \\
\hline
\end{tabular}

\subsection{Seasonal Trend in Different Regions}

The trends in the AOD values are presented in Fig. 9. The left-slash (/) block shows the trends of the seasonal AOD in six typical study regions, and the right-slash ( $($ ) block presents the corresponding significance.

For poor air quality regions, such as JJT and SC, increasing trends are detected in all seasons. The maximal magnitude is 0.19/11-year in summer for JJT and 0.068/11-year in spring for SC. An increasing trend prevails in most of the seasons over YRD and PRD except in spring for YRD and in summer for PRD. The trend is associated with the rapid development of regional industrialization. The southeasterly winds during summer can remove local aerosol pollution, which causes a decreasing trend over PRD. ${ }^{35,36}$ Over SX, a positive trend is only observed in autumn with a 95\% confidence level. The AOD exhibits an increasing trend during summer and winter, and a reverse trend is found for the rest of the season over GX. The aerosol emissions from biomass burning are minimized, which leads to a decreasing AOD trend.
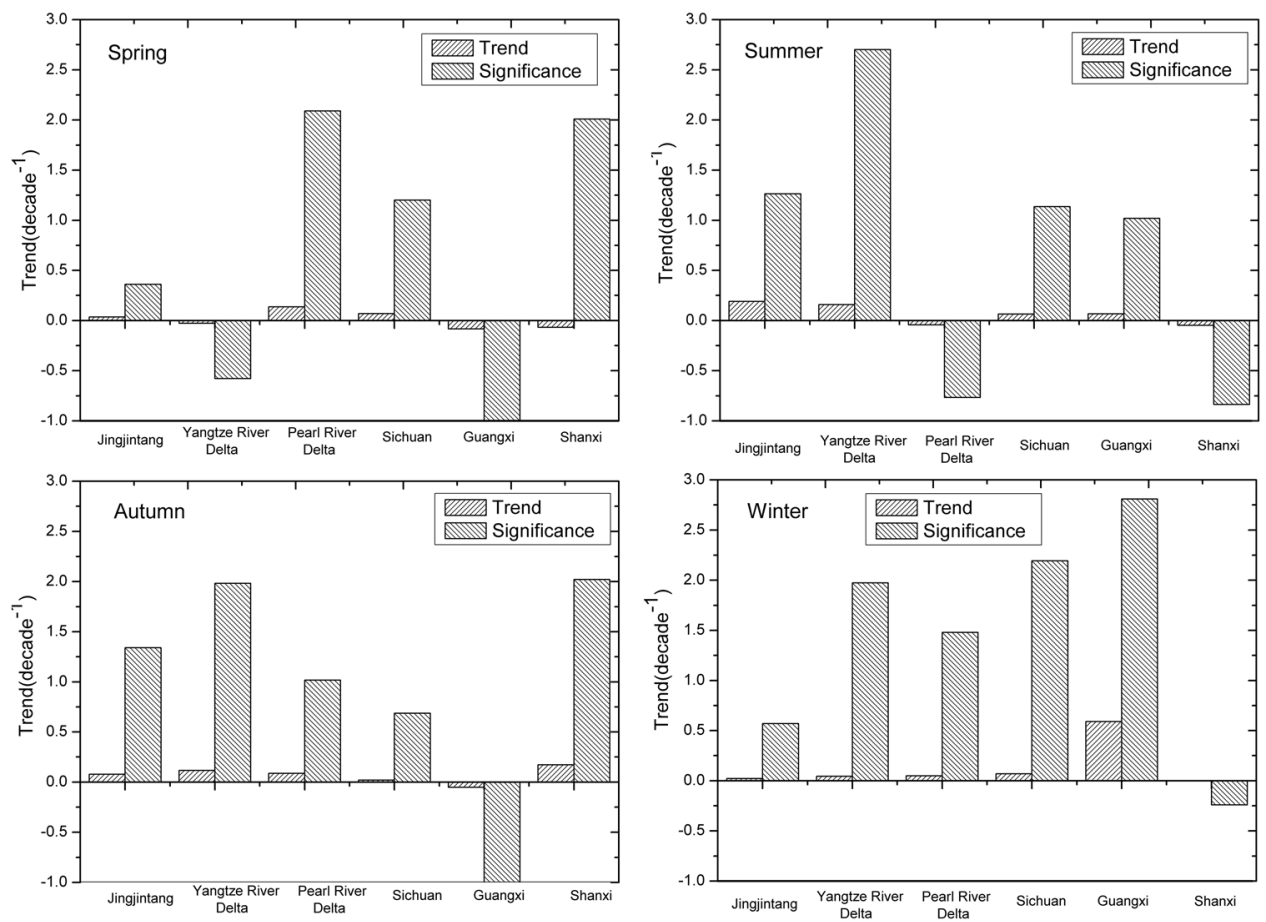

Fig. 9 Columns of the trend and its significance for annual averaged AOD at $550 \mathrm{~nm}$ based on MISR data. The trends of AOD $\times 100$ are shown. 
The highest $|\omega / \sigma|$ value is 2.7 and clearly corresponds with an increasing trend $(0.16 / 11$ year) over YRD. From the analysis in Fig. 9, in all of the regions, the $|\omega / \sigma|$ values are $<2$, which imply that a longer study period is required for the trends to be statistically significant. ${ }^{32}$

\section{Conclusion}

In this paper, the spatial and temporal distribution and the long-term trend of the AOD have been researched using 11-year aerosol product from MISR data over different regions in central and eastern China. The trend in AOD is analyzed carefully both regionally and seasonally concerning the increased precision of AOD products, which can be reached using FFT methods.

We evaluated the MISR against the AERONET AOD regarding six stations located in China. The agreement between the MISR and AERONET AOD is better with a correlation coefficient of 0.94 and lower RMSE of 0.04 compared with the MODIS. The results showed that the MISR AOD exhibited greater accuracy over China.

The analysis of the MISR AOD detects patterns of spatial, temporal, and seasonal variability of aerosol properties over central and eastern China. The regions with high AOD values are mainly distributed in economically developed and densely populated areas, such as YRD and SC. The maximum AOD occurs in summer for JJT, whereas the minimum occurs in winter for SX. The distribution of the seasonal AOD is contrary to the results derived from the MODIS $\mathrm{AOD}$, and an increase over SC is inconsistent with a negligible trend for the years of 2000 to 2008 .

A slightly increasing trend around 5.3\% in the AOD values has been noticed over the study area. The increasing trend is more evident for annually and seasonally averaged AOD.

The largest positive tendencies are found over JJT (23.8\%) and YRD (24.4\%), which indicate that both of them have similar geographical characteristics, development patterns, and natural situation. Over PRD and GX, the gradual increase in the proportion of coarse-mode particles causes the positive tendencies in AOD.

The analysis of the spring and winter seasons revealed the changes and contribution in aerosol properties for the study areas. During spring, the dust is not the dominant aerosol type over JJT and YRD; the high aerosol loading in these regions is mainly caused by fine-mode aerosol. Biomass burning exhibited less impact on aerosol loading for GX. The area with the most decreasing trends $(-18.7 \%)$ is $\mathrm{SX}$, which relates to emission control strategies implement.

During winter, the increasing trends in AOD values are found in most of the study areas except for SX in which coarse particles are the dominant aerosol. There are increasing trends in the AOD for JJT, YRD, and SC with increasing ÅE. The increase in the fine aerosols is related to fossil fuel and biomass burning for heating, which produce heavy loadings of smoke. ${ }^{37}$

Compared to the 558-nm wavelength band, the AOD values of different wavelength bands are consistent with the 558-nm band on temporal-spatial distributions, variation trends, and seasonal characteristics.

\section{Acknowledgments}

This work has been supported by National Basic Research Program of China (973) under project 2010CB950800. The authors also acknowledge the NASA-U.S for the use of Level-3 spectral aerosol data from MISR instrument onboard Terra satellites, and also the Aerosol Robotic Network (AERONET) for applying the AOD data from the two monitoring sites.

\section{References}

1. P. Forster et al., "Changes in atmospheric constituents and in radiative forcing," in Climate Change 2007: The Physical Science Basis, Contribution of Working Group 1 to the Fourth Assessment Report of the IPCC, S. Solomon et al., Eds., pp. 129-234, Cambridge University Press, Cambridge (2007).

2. R. J. Charlson et al., "Climate forcing by anthropogenic aerosols," Science 255(5043), 423-430 (1992), http://dx.doi.org/10.1126/science.255.5043.423. 
3. Y. J. Kaufman, D. Tanré, and O. Boucher, "A satellite view of aerosols in the climate system," Nature 419, 215-223 (2002), http://dx.doi.org/10.1038/nature01091.

4. T. X.-P. Zhao et al., "Study of decadal trend in aerosol optical thickness observed from operational AVHRR satellite instrument," J. Geophys. Res. 113(D7), 201-214 (2008), http://dx.doi.org/10.1029/2007JD009061.

5. C. D. Papadimas et al., "Spatial and temporal variability in aerosol properties over the Mediterranean basin based on 6-year (2000-2006) MODIS data," J. Geophys. Res. 113(D11), 205-216 (2008), http://dx.doi.org/10.1029/2007JD009189.

6. X. Su et al., "Aerosol variability over East Asia as seen by POLDER space-borne sensors," J. Geophys. Res. 115(D24), 215-228 (2010), http://dx.doi.org/10.1029/2010JD014286.

7. J.-P. Guo et al., "Spatiotemporal variation trends of satellite-based aerosol optical depth in China during 1980-2008," Atmos. Environ. 45(37), 6802-6811 (2011), http://dx.doi.org/10 .1016/j.atmosenv.2011.03.068.

8. A.A. Kokhanovsky et al., "Aerosol remote sensing over land: a comparison of satellite retrievals using different algorithms and instruments," Atmos. Res. 85(3-4), 372-394 (2007), http://dx.doi.org/10.1016/j.atmosres.2007.02.008.

9. M. I. Mishchenko et al., "Long-term satellite record reveals likely recent aerosol trend," Science 315(5818), 1543-1543 (2007), http://dx.doi.org/10.1126/science.1136709.

10. A. A. Kokhanovsky et al., "The inter-comparison of major satellite aerosol retrieval algorithms using simulated intensity and polarization characteristics of reflected light," Atmos. Meas. Tech. 3, 909-932 (2010), http://dx.doi.org/10.5194/amt-3-909-2010.

11. O. Torres et al., "A long-term record of aerosol optical depth from TOMS observations and comparison to AERONET measurements," J. Atmos. Sci. 59, 398-413 (2002), http://dx.doi .org/10.1175/1520-0469(2002)059<0398:ALTROA>2.0.CO;2.

12. J. Zhang and J. S. Reid, "MODIS aerosol product analysis for data assimilation: assessment of level 2 aerosol optical thickness retrievals," J. Geophys. Res. 111(D22), 207-219 (2006), http://dx.doi.org/10.1029/2005JD006898.

13. R. A. Kahn et al., "MISR aerosol product attributes, and statistical comparisons with MODIS," IEEE Trans. Geosci. Rem. Sens. 47(12), 4095-4114 (2009), http://dx.doi.org/ 10.1109/TGRS.2009.2023115.

14. J. Zhang, J. S. Reid, and B. N. Holben, "An analysis of potential cloud artifacts in MODIS over ocean aerosol optical thickness products," Geophys. Res. Lett. 32(15), L15803 (2005), http://dx.doi.org/10.1029/2005GL023254.

15. R. C. Levy et al., "Evaluation of the Moderate-Resolution Imaging Spectroradiometer (MODIS) retrievals of dust aerosol over the ocean during PRIDE (2003)," J. Geophys. Res. 108(D19), 8594-8606 (2003), http://dx.doi.org/10.1029/2002JD002460.

16. D. J. Diner et al., "Multiangle Imaging SpectroRadiometer (MISR) instrument description and experiment overview," IEEE Trans. Geosci. Rem. Sens. 36(4), 1072-1087 (1998), http://dx.doi.org/10.1109/36.700992.

17. A. K. Prasad and R. P. Singh, "Comparison of MISR-MODIS aerosol optical depth over the Indo-Gangetic basin during the winter and summer seasons (2000-2005)," Rem. Sens. Environ. 107, 109-119 (2007), http://dx.doi.org/10.1016/j.atmosenv.2004.12.029.

18. Y. Liu et al., "Review of the applications of Multiangle Imaging SpectroRadiometer to air quality research," China Earth Sci. 52(1), 132-154 (2008), http://dx.doi.org/10.1007/ s11430-008-0149-6.

19. S. A. Christopher and J. Wang, "Intercomparison between multi-angle imaging spectroradiometer (MISR) and sunphotometer aerosol optical thickness in dust source regions over China: implications for satellite aerosol retrievals and radiative forcing calculations," Tellus Series B Chem. Phys. Meteorol. 56(5), 451-456 (2004), http://dx.doi.org/10.1111/teb.2004 .56.issue-5.

20. C. C. Li et al., "Characteristics of distribution and seasonal variation of aerosol optical depth in eastern China with MODIS products," Chin. Sci. Bull. 48(22), 2488-2495 (2003b).

21. S. Kinne et al., "An AeroCom initial assessment—optical properties in aerosol component modules of global models," Atmos. Chem. Phys. 6, 1815-1834 (2006), http://dx.doi.org/ 10.5194/acp-6-1815-2006. 
22. D. Kim and V. Ramanathan, "Solar radiation budget and radiative forcing due to aerosol and clouds," J. Geophys. Res. 113(D2), 203-236 (2008), http://dx.doi.org/10.1029/ 2007JD008434].

23. Y. Chen et al., "Quantifying aerosol direct radiative effect with Multiangle Imaging Spectroradiometer observations: top of atmosphere albedo change by aerosols based on land surface types," J. Geophys. Res. 114(D2), 109-117 (2009), http://dx.doi.org/ 10.1029/2008JD010754.

24. R. A. Kahn et al., "Multiangle Imaging SpectroRadiometer global aerosol product assessment by comparison with the Aerosol Robotic Network," J. Geophys. Res. 115(D23), 209-236 (2010), http://dx.doi.org/10.1029/2010JD014601.

25. J. V. Martonchik et al., "Techniques for the retrieval of aerosol properties over land and ocean using multiangle imaging," IEEE Trans. Geosci. Rem. Sens. 36(4), 1212-1227 (1998), http://dx.doi.org/10.1109/36.701027.

26. J. V. Martonchik, R. A. Kahn, and D. J. Diner, "Retrieval of aerosol properties over land using MISR observations," in Satellite Aerosol Remote Sensing Over Land, A. Kokhanovsky, Ed., Springer, Berlin (2009).

27. R. A. Kahn et al., "MISR global aerosol optical depth validation based on two years of coincident AERONET observations," J. Geophys. Res. 110(D10), S04-S11 (2005), http://dx.doi.org/10.1029/2004JD004706.

28. R. A. Kahn et al., "Aerosol source plume characteristics from space based multiangle imaging," J. Geophys. Res. 112(D11), 205-217 (2007), http://dx.doi.org/10.1029/ 2006JD007647.

29. A. A. Kokhanovsky et al., "Aerosol remote sensing over land: a comparison of satellite retrievals using different algorithms and instruments," Atmos. Res. 85, 372-397 (2007), http://dx.doi.org/10.1016/j.atmosres.2007.02.008.

30. L. A. Remer et al., "The MODIS aerosol algorithm, products, and validation," J. Atmos. Sci. 62(4), 947-973 (2005), http://dx.doi.org/10.1175/JAS3385.1.

31. E. C. Weatherhead et al., "Factors affecting the detection of trends: statistical considerations and applications to environmental data," J. Geophys. Res. 103(D14), 17149-17161 (1998), http://dx.doi.org/10.1029/98JD00995.

32. J. Zhang and J.S. Reid, "A decadal regional and global trend analysis of the aerosol optical depth using a data-assimilation grade over-water MODIS and Level 2 MISR aerosol products," Atmos. Chem. Phys. 10, 10949-10963 (2010), http://dx.doi.org/10.5194/acp-1010949-2010.

33. J. Lelieveld et al., "The Indian Ocean Experiment: widespread air pollution from south, and southeast Asia," Science 291(5506), 1031-1036 (2001), http://dx.doi.org/10.1126/science .1057103.

34. R. R. Dickerson et al., "The impact of aerosols on solar ultraviolet radiation, and photochemical smog," Science 278(5339), 827-830 (1997), http://dx.doi.org/10.1126/science .278.5339.827.

35. Y. Wang et al., "Seasonal variations in aerosol optical properties over China," J. Geophys. Res. 116(D18), 27-33 (2011), http://dx.doi.org/10.1029/2010JD015376.

36. D. Wu, "A review and outlook on the aerosol study over South China," J. Trop. Meteorol. 19(Suppl), 145-151 (2003), in Chinese.

37. G. Cao et al., "Inventory of atmospheric pollutants discharged from biomass burning in China continent," China Environ. Sci. 25(4), 389-393 (2005), in Chinese.

Biographies and photographs of the authors are not available. 